\title{
Frontières
}

\section{Bibliographie indicative sur la mort dans la littérature}

\section{Pierre-Olivier Hudon}

Volume 18, numéro 1, automne 2005

URI : https://id.erudit.org/iderudit/1074329ar

DOI : https://doi.org/10.7202/1074329ar

Aller au sommaire du numéro

Éditeur(s)

Université du Québec à Montréal

ISSN

1180-3479 (imprimé)

1916-0976 (numérique)

Découvrir la revue

Citer ce document

Hudon, P.-O. (2005). Bibliographie indicative sur la mort dans la littérature. Frontières, 18(1), 80-80. https://doi.org/10.7202/1074329ar d'utilisation que vous pouvez consulter en ligne.

https://apropos.erudit.org/fr/usagers/politique-dutilisation/ 


\section{BIBLIOGRAPHIE INDICATIVE SUR LA MORT DANS LA LITTÉRATURE}

Pierre-Olivier Hudon

CHÂTELET, Noël (2004), La dernière leçon, Paris, Seuil.

CLICHE, Anne Élaine et Bertrand GERVAIS (dir.) (2001), Figures de la fin: approches de l'irreprésentable, Montréal, UQAM, Département d'études littéraires.

COLLION DIÉRICKX, Chantal (2001), La femme, la parole et la mort dans Axël et L'Ève future de Villiers de I'Isle-Adam, Paris, H. Champion éditeur.

CONORT, Benoît (2002), Pierre Jean Jouve: mourir en poésie: la mort dans l'œuvre poétique de Pierre Jean Jouve, Villeneuve-d'Ascq, Presses universitaires du Septentrion.

COURTEMANCHE, Gil (2005), Une belle mort, Montréal, Boréal.

DE KEYSER, Véronique (2004), À la vie comme à la mort!, Bruxelles, Labor. GOMEZ MANGO, Edmundo (2003), La mort enfant, Paris, Gallimard.

GREEN, André (2004), La lettre et la mort: promenade d'un psychanalyste à travers la littérature, Proust, Shakespeare, Conrad, Borges, Paris, Denoël.

GRENIER, Louise et Suzanne TREMBLAY (dir.) (2005), Le projet d'Antigone: parcours vers la mort d'une fille d'ipe, Montréal, Liber.

HENTSCH, Thierry (2002), Raconter et mourir: aux sources narratives de I'imaginaire occidental, Montréal, Les Presses de l'Université de Montréal.

HENTSCH, Thierry (2005), Le temps aboli: I'Occident et ses grands récits, Montréal, Les Presses de l'Université de Montréal.

HUISMAN-PERRIN, Emmanuelle (2002), La Mort expliquée à ma fille, Paris, Seuil.

JACQUES, Alexandre et Julie LAROSE (dir.) (2001), Littérature américaine: imaginaire de la fin: dossier, Montréal, Québec, Postures.

JACQUIN, Gérard (dir.) (2003), Le récit de la mort: écriture et histoire, Rennes, Presses universitaires de Rennes.

JOULIN, Cécile (2002), La mort dans les œuvres oratoires de Bossuet, SaintÉtienne, Publications de l'Université de Saint-Étienne.

KOFF, Clea (2005), La mémoire des os, Paris, Héloïse d'Ormesson.

MAVRIKAKIS, Catherine (2005), Fleurs de crachat, Montréal, Leméac.

MAVRIKAKIS, Catherine (2000), Deuils cannibales et mélancoliques, Montréal, Trois.

PASQUIER, Pascal (2001), Mourir pour vivre? Les rites de passage et la foi chrétienne aujourd'hui, Paris, Éditions de l'Atelier, Éditions Ouvrières.

PELLETIER, Benjamin (2005), La mère des batailles, Paris, Éditions de I'Olivier/Le Seuil.

PHILLIPS, Adam (2002), La mort qui fait aimer la vie: Darwin et Freud, Paris, Payot.

ROGAK, Lisa (dir.) (2004), Death Warmed Over: Funeral Food, Rituals, and Customs from Around the World, Berkeley, Ten Speed Press.

SANCHEZ-PARDO, Esther (2003), Cultures of the Death Drive: Melanie Klein and Modernist Melancholia, Durham, Duke University Press.

SILIOTTI, Alberto (2000), Demeures d'éternité, traduction de Ida Giordano, Françoise Liffran et Anne-Lise Quendolo, Paris, Gallimard.

SCHNEIDER, Michel (2003), Morts imaginaires, Paris, Bernard Grasset.

THOMAS, Louis-Vincent (2000), Les chairs de la mort: corps, mort, Afrique, Le Plessis-Robinson, France, Institut Synthélabo pour le progrès de la connaissance.

VIOLET, Lydie et Marie DESPLECHIN (2005), La vie sauve, Paris, Seuil.

VISSET, Pascal (2003), Le temps, I'autre et la mort dans trois fictions du milieu du XX ${ }^{\mathrm{e}}$ siècle: El jardín de senderos que se bifurcan de J.L. Borges, Under the volcano de M. Lowry et Le rivage des Syrtes de J. Gracq: la question de la fiction, Paris. Honoré Champion éditeur.

VULTUR, loana (2003), Proust et Broch: les frontières du temps, les frontières de la mémoire, Paris, L'Harmattan. 